\title{
Aprendizagem da docência de professores do \\ Ensino Técnico em nivel médio
}

\section{Teacher teaching learning middle technical education}

\author{
Darlan Oliveira Rocha ${ }^{1}$
}

\section{Resumo}

O artigo discute as trajetórias de aprendizagem da docência no Ensino Técnico no nivel médio. Foram colhidas entrevistas individuais de professores para a realização deste estudo descritivo-analítico de natureza qualitativa. O debate acerca da formação docente tem como referências teóricas os trabalhos de Zabalza (2009) sobre a questão da docência como estado da arte ou ciência, de Huberman (1992) a respeito da evolução profissional do docente como um processo contínuo e de Shulman (2005) sobre os saberes e conhecimentos necessários ao exercícios da docência. O aprendizado da teoria associado à prática e a articulação entre instituição, professor e aluno se mostraram como importantes características do universo do Ensino Técnico.

\footnotetext{
1 Diretor Escolar da unidade do Senac São Paulo de Itaquera (São Paulo/ SP), integrou o Programa de Movimentação Gerencial da instituição tendo atuado também como Técnico de Desenvolvimento Profissional no Centro Universitário Senac - Campus Santo Amaro a frente da Coordenação das Pós-graduações Lato Sensu e professor titular da Fundação Educacional de Fernandópolis (FEF), Fundação Educacional de Votuporanga (UNIFEV) e Universidade Estácio de Sá (UNESA). Foi supervisor da área de recursos humanos e qualidade do Grupo Hoken, eleito por três anos consecutivos (2004, 2005 e 2006) como uma das 150 Melhores Empresas Para Se Trabalhar e uma das 50 Melhores Para a Mulher Trabalhar, segundo pesquisas das revistas Exame-Você S/A. Doutorando e Mestrado em Educação, Arte e História da Cultura (Mackenzie), Especialista (Lato Sensu) em Gestão Avançada de Recursos Humanos(INPG), Lead Auditor pela Stat-A-Matrix Institute (EUA) e Bacharel em Direito (Unifev). E-mail: darlan.orocha@sp.senac.br.
}

Interfaces da Educ., Paranaíba, v.10, n.28, p.307 à 341, 2019

ISSN 2177-7691

Recebido em julho de 2019 e aprovado em agosto de 2019 
Palavras-chave: Ensino Técnico. Trajetórias de Aprendizagem da Docência. Formação Docente. Desenvolvimento Profissional de Docentes. Docência.

\section{Abstract}

The article discusses the learning trajectories of teaching in Technical Education in high school. Individual teacher interviews were collected in order to carry out this descriptive-analytical study of a qualitative nature. The debate about teacher education has as theoretical references the work of Zabalza (2009) on the issue of teaching as state of the art or science, by Huberman (1992) regarding the professional evolution of the teacher as a continuous process and Shulman (2005) on the acquirements and knowledge necessary for teaching practice. The learning of the theory associated to practice and the articulation between institution, teacher and student were shown as important characteristics of the Technical Teaching universe.

Keywords: Technical Education. Learning Paths of Teaching. Teacher Training. Professional Development of Teachers. Teaching.

\section{Introdução}

A Educação Profissional Técnica (EPT) de nível médio, está prevista na Lei de Diretrizes e Bases (LDB) que organiza as condutas da educação nacional. Esta modalidade de ensino complementa a educação básica, podendo ser desenvolvida em diferentes niveis, tanto jovens como adultos de escolaridade diversa (Messeder, 2012, p.115). A EPT é responsável pela formação de técnicos no Ensino Médio, mas também assume um papel importante na reintrodução de adultos no mercado de trabalho, na atualização tecnológica de profissionais e habilitação de estudante no nível médio e superior.

Em $2012^{2}$ o Censo Escolar da Educação Básica revelou que 1.063.655 alunos participavam da educação profissional (concomitante e subsequente),

2 O Censo Escolar da Educação Básica é uma pesquisa declaratória realizada anualmente pelo Instituto Nacional de Estudos e Pesquisas Educacionais Anísio Teixeira (Inep), sendo

Interfaces da Educ., Paranaíba, v.10, n.28, p.307 à 341, 2019 
o que representa um aumento de 65,21\% em comparação ao período de 2007 . A expansão das vagas e de participantes se explica principalmente devido a articulação de governo estadual e federal que estabeleceu, por meio de instituições como as do "Sistema S" (SENAI, SENAC, SESC, SESI, entre outras) e o Programa Nacional de Acesso ao Ensino Técnico (Pronatec), um aumento no número de vagas gratuitas (acordo de gratuidade).

Se por um lado existe o incentivo real e crescente por aumentar o número de estudantes na EPT, por outro, amplia-se a necessidade da rede de ensino, pública ou privada, de aprimorar seus esforços em termos de atuação educacional, gestão e infraestrutura para melhor atender o aluno com vistas às necessidades do mundo do trabalho.

Moura (2015, p. 28) reafirma essa questão lembrando que esse universo profissional exige indivíduos que possam atuar em um ambiente de geração de conhecimento e, também, de transferência a outros contextos em constante transformação. O autor ressalta a necessidade dos profissionais egressos da EPT de ultrapassarem limites e alcançarem a autonomia que os permita atuar na perspectiva da transformação social. Para ele, o EPT tem o poder de contribuir com a (re) inserção social, laboral ${ }^{3}$ e política dos seus egressos que podem ser considerados verdadeiros agentes de mudança da classe trabalhadora. Nesse processo educativo, a interface entre o aluno e o mundo do trabalho é feita pelo professor que desempenha o papel de interlocutor.

Com a valorização do ensino técnico nos últimos anos, aumenta também a responsabilidade do docente como profissional contemporâneo que facilita o desenvolvimento de novas competências em seus alunos. No entanto, dada a notória escassez de estudos sobre a formação de professores no ensino

obrigatório aos estabelecimentos públicos e privados de educação básica, conforme determina o art. $4^{\circ}$ do Decreto $n^{\circ} 6.425 / 2008$.

${ }^{3} \mathrm{O}$ autor citado refere-se à inserção como sendo a participação plena do indivíduo na sociedade. Desta forma, vai além da admissão de um posto de trabalho, pois, mais do que o acesso ao emprego e/ou outras fontes de geração de renda, também inclui a participação social, política e cultural, indispensáveis ao pleno exercício da cidadania emancipada, consciente, crítica e responsável.

Interfaces da Educ., Paranaíba, v.10, n.28, p.307 à 341, 2019 
Aprendizagem da docência de professores do Ensino Técnico...

técnico, há quase um silenciamento em relação a temática, como apontam André (2009) e Brzezinski (2006).

O objetivo deste artigo é analisar a trajetória de professores do ensino técnico observando suas práticas com o intuito de contribuir com a discussão acerca da formação docente do ensino técnico no nível médio. A questão que respondemos foi: como se caracterizam as trajetórias de aprendizagem dos professores do Ensino Técnico em nivel médio?

Os referenciais teóricos principais que delimitam os objetivos do estudo baseiam-se nos trabalhos de Zabalza (2009) sobre a questão da docência como estado da arte ou ciência (caráter pessoal versus técnico), de Huberman (1992) que considera o desenvolvimento profissional do docente como um processo de contínua evolução e exploração e de Shulman (2005) sobre os saberes e conhecimentos necessários ao exercício da docência. Finalmente, também serão levadas em consideração as legislações vigentes que regulamentam a atividade profissional em questão. Por último, apresentamos a análise dos dados gerados na pesquisa e conclusão do estudo.

\section{Desenvolvimento Profissional Docente}

A profissão do docente carrega uma peculiaridade importante com relação a identidade profissional dela mesma. A docência é um fazer composto por distintos domínios teóricos como a Sociologia, Psicologia e Filosofia, formando um campo mestiço de saberes, práticas e politicas. Nesse contexto, a Educação atua como área que conecta essas diversas esferas de conhecimento em métodos, conceitos e disciplinas múltiplas. (Charlot, 2006).

Para Charlot (2006), uma disciplina chamada Educação só pode ter esse nome se levar em conta essas três formas de atividades, seus processos e a tripla articulação. É uma área de conhecimento que precisa atentar-se à contradição, às tensões, às defasagens e às heterogeneidades das lógicas. Para tanto, são indispensáveis tanto a constituição de um arquivo coletivo de pesquisa em Educação e quanto a definição de frentes de pesquisas variadas. Nesse sentido, o estudo da formação docente precisa ser baseado em áreas diversas como Sociologia, Psicologia, entre outras.

Interfaces da Educ., Paranaíba, v.10, n.28, p.307 à 341, 2019 
Ao estudar a formação do professor é preciso entender que se trata de um processo que impacta diretamente a prática do professor ao longo de sua carreira. Essa investigação é feita observando como a formação docente molda o conhecimento e prática dos professores. Shulman (2002) vai além ao apontar que o tipo de preparação dada ao professor pode afetar o aprendizado dos seus alunos no futuro. Além disso, outros fatores também contribuem para essa questão como as características individuais dos futuros professores, dos cursos e das instituições, assim como a natureza do ensino, o que os professores aprendem nesses cursos, suas experiências profissionais anteriores, as práticas e políticas da escola, e o contexto político das diferentes esferas administrativas (municipio, estado, etc.).

Dada a grande complexidade da área de formação docente, nenhuma metodologia, por melhor que seja, é capaz de, isoladamente, de fornecer todas as ferramentas necessárias para compreender inteiramente como e de que maneira ela influencia os resultados educacionais. Shulman (2005) ainda compara o aperfeiçoamento do saber da docência com os apontamentos de Piaget acerca do desenvolvimento da inteligência infantil. Ao observar cuidadosamente a criança, Piaget percebeu que poderia adquirir um grande rol de conhecimentos sobre seu desenvolvimento e sobre como ela organiza sua inteligência. Da mesma forma, o próprio processo de desenvolvimento do estudante à docente evidencia a enorme complexidade de conhecimentos e habilidades que são necessários para formação de um professor competente.

Tal análise deve definir o conhecimento base para o ato de ensinar identificando suas fontes, assim como explorar os processos de raciocínio e ação didática na forma como os docentes utilizam seus conhecimentos (Shulman, 2005).

Zabalza (2004) completa tais reflexões sobre a formação docente afirmando que o profissional da educação precisa reavaliar constantemente que saberes são necessários para se tornar um docente que atenda as demandas da contemporaneidade. Para ele, a complexidade do ensino exige conhecimento acerca da disciplina e suas atividades, da maneira como os 
Aprendizagem da docência de professores do Ensino Técnico...

estudantes aprendem e o modo como serão conduzidos os recursos de ensino a fim que se realize um bom trabalho.

Resumidamente, a pesquisa em questão fundamentou-se teoricamente em 3 aspectos:

1 - A legislação em torno da Educação Profissional e Tecnológica. Aspectos como o resgate histórico, atualidade, estruturação e implementação, serão abordados sobre a legislação existente em torno desta modalidade, a legislação das Escolas de Aprendizes Artífices a Educação Profissional e Tecnológica na atualidade, bem como, a legislação em torno da formação de professores desta modalidade de ensino;

2 - A educação como campo complexo e de conhecimentos diversos será abordada em referência aos estudos de Bernard Charlot (2006) e Zabalza (2009), descrevendo inicialmente sobre as influências de áreas distintas do conhecimento sobre a educação e posteriormente a questão relacionada ao seu estado de arte ou ciência;

3 - A formação docente, referenciando-se aos "ciclos de vida" do professor, a formação inicial e continuada e os conhecimentos (ou saberes) docente; abordando as categorias de base do conhecimento para o ensino segundo Shulman (2005); docência e base de conhecimento para o ensino; os conhecimentos (ou saberes) necessários à prática docente e a reflexão sobre a ação e o professor profissional e os meios de profissionalização contínua, baseados na prática reflexiva. Por fim, tem-se os resultados da pesquisa aplicada considerando as aprendizagens da docência de professores do ensino técnico em nível médio, a partir das referências estudadas e da análise da história oral/ entrevistas individuais dos participantes, discorrendo-se sobre as questões identificadas. Desta forma, pretende-se com esta, contribuir para o tema e para a sua relevância, por meio da abordagem de seus conteúdos e dos resultados desta pesquisa.

\section{Método, procedimentos metodológicos: a aprendizagem da docência dos professores do Ensino Técnico}

Interfaces da Educ., Paranaíba, v.10, n.28, p.307 à 341, 2019 
Por meio da observação dos discursos e práticas de alguns profissionais (entrevistas individuais e história oral) este artigo analisa a trajetória desses docente e convida o leitor a refletir sobre esse universo do professor do ensino técnico. Tal reflexão pretende contribuir ao diálogo sobre teorias de aprendizagem da docência, sobre o desenvolvimento profissional do docente, das práticas públicas existentes e gerar conhecimento que pode ser importante para professores, gestores educacionais, ou demais interessados no assunto.

Os dados apresentados a seguir foram colhidos por meio de um estudo descritivo-analítico, de natureza qualitativa, tendo como sujeitos professores do ensino técnico em nível médio com no mínimo 10 anos de atuação na modalidade. A coleta foi realizada de forma voluntária, onde os professores ofereceram, por meio de entrevistas individuais, suas histórias orais de trajetórias de aprendizagem da docência. A partir da definição das unidades participantes os profissionais foram contatados e avaliados quanto aos os prérequisitos necessários e, por fim, considerados como sujeitos de estudo e informação desta pesquisa. Os professores selecionados possuem experiência profissional individual, uma maneira pessoal de ensinar que pode ser vista como macete da profissão.

Para Tardif (2007), esse "saber experienciado" é típico da segunda fase da evolução da carreira docente chamada estabilização e consolidação. No entanto, essa experiência não deve ser confundida com experimentação e nem com experiência pessoal, mas sim, com experiência vivida no trabalho e que ajuda a moldar com o tempo a identidade do profissional.

\section{Resultados e discussão}

Para o entendimento das aprendizagens de professores do ensino técnico em nível médio foram investigados 13 eixos de análises, definidos pelas respostas dos participantes (público-alvo) ${ }^{4}$ à questões descritivas. O

\footnotetext{
${ }^{4}$ Quando do uso de excertos das respostas dos participantes, a fim de manter a sua originalidade a redação de cada um deles foi mantida. Em decorrência disso, alguns apresentam erros de redação no texto.
}

Interfaces da Educ., Paranaíba, v.10, n.28, p.307 à 341, 2019 
conteúdo foi, então, avaliado qualitativamente e quantitativamente. A seguir serão apresentados cada um desses eixos, assim como a distribuição qualitativa dos dados acompanhados de trechos das falas dos professores (identificados de 1 a 21) que ilustram as questões discutidas no artigo.

- Docência e trabalhos educativos realizados pelos participantes.

As atividades do profissional docente não se restringem à sala de aula. Sendo que é possivel observar que dentre outras atividades, dos profissionais pesquisados encontra-se:

- 57,14\% trabalham em regime de dedicação exclusiva à docência;

- 33,33\% conciliam à docência, atividades extracurriculares (participação em eventos, palestras, entre outros) ou atuação em mais de uma escola (Ensino Técnico ou Superior), ou até mesmo, atividades de coordenação;

- 9,52\%, realizam trabalhos voluntários, voltados à educação porém, fora do ambiente escolar.

O fato de possuírem uma situação estável de trabalho, dedicando-se principalmente à docência, é de suma importância pois, demonstra "estabilidade" e reforça a questão da formação e profissionalização docente, uma vez que, o exercício de forma irregular, não no sentido de infringência à lei mas, de não habitualidade, regularidade, pode definir uma situação precária (Tardif, 2007, p. 89):

[...] vivem uma outra coisa e sua experiência relativa à aprendizagem da profissão é complexa e mais difícil, pois comporta sempre uma certa distância em relação à identidade e à situação profissional bem definida dos professores regulares. É difícil pensar na consolidação de competências pedagógicas enquanto os professores com serviços prestados não tiverem adquirido um mínimo de estabilidade [...].

- $\quad$ Como os professores aprenderam ou tem aprendido a ensinar.

Interfaces da Educ., Paranaíba, v.10, n.28, p.307 à 341, 2019 
As aprendizagens da docência são construídas de diversas formas e, entre elas, merecem destaque:

- 66,66\% citam a trajetória profissional como ponto de partida para a inserção na educação/ formação concomitante à atuação como docente;

- 14,28\% cursaram o magistério, seguido de formação na licenciatura;

- $14,28 \%$ tiveram um professor como modelo, seja na escola ou dentro de casa;

- 4,76\% consideram o "dom" como ponto principal para a prática da docência.

É notável, no ensino técnico, o aprendizado da docência acontecer por meio da formação "em exercício", que se evidenciam em falas como:

[...] eu trabalhava no Hospital, o coordenador do setor que eu trabalhava era coordenador do curso Técnico em Enfermagem [...] me convidou para dar uma palestra [...], fiquei super feliz, mas com muito medo, ele mesmo me ensinou, orientou como trabalhar, a partir desse dia comecei ministrar aulas, fui contratada, e aprendendo cada dia mais, trazendo experiências profissionais. (Prof. 7).

Meu aprendizado teve início nas salas de treinamento da empresa que trabalhava, no qual, nosso desafio era educar os colaboradores a compreender sobre prevenção de acidentes. Neste período nossas abordagens tinham que ser diferentes ainda que o conceito era o mesmo. Na chegada ao SENAC obtive outras técnicas de ensino aprendizagem, que somando as novas habilidades consigo fazer uma integração dos saberes, por meio das vivências profissionais e estratégias de ensino da instituição. (Prof. 10)

Segundo Imbernón (2004, p. 37), “formar-se é um processo que começa a partir da experiência prática dos professores. Seria mais adequado dizer que começa na "práxis", já que a experiência prática possui uma teoria, implícita ou explícita, que a fundamenta”. Ainda em Tardif (2000, p. 13), é importante

Interfaces da Educ., Paranaíba, v.10, n.28, p.307 à 341, 2019 
lembrar que a história escolar dos professores, mesmo antes de começarem a lecionar, inspira parte dos conhecimentos sobre o ensino desses docentes, uma vez que frequentaram o ambiente escolar por muitos anos antes de começarem a atuar profissionalmente.

Acredito que iniciei meu processo de "treinamento docente" na participação dos seminários da faculdade, onde sempre me identifiquei e de alguma forma sempre me coloquei a ensinar aos meus colegas. [...] Continuo aprendendo a cada dia, mas no início sempre busquei me espelhar em alguns professores exemplos, em metodologia onde aprendia com mais facilidade. Hoje me espelho ainda em alguns palestrantes, amigos de profissão e em algumas atitudes facilitadoras.

(Prof. 12)

Boa parte das concepções, representações e certezas sobre a prática docente podem ser atribuidas a esse movimento. Prossegue o mesmo autor (Tardif, 2000, p. 79) dizendo que o tempo de aprendizagem profissional vai além do tempo formal de carreira e inclui a vivência pessoal do professor, sua história familiar, experiências vividas na escola, influência de outros professores, fazendo com que esse processo de aquisição de conhecimento, de certa forma, comece anteriormente ao exercício da sua profissão.

Como tenho experiência familiar de ensino um pouco adquiri os conhecimentos pelos relatos de minha mãe e primas e por outro lado a vivência dia a dia de sala de aula que vai agregando o aprendizado e moldando o formato de ensinar e aprender. (Prof. 17).

Inicialmente aprendi porque venho de uma familia de professores [...] em todo momento estamos aprendendo com os alunos e as pessoas que nos rodeiam também. (Prof. 21).

- O que um professor precisa saber para ensinar.

Interfaces da Educ., Paranaíba, v.10, n.28, p.307 à 341, 2019 
Quando questionados sobre os conhecimentos (saberes) necessários para o ensino, predominam entre os entrevistados:

- 71,42\% citam o embasamento teórico ou compreensão e uso de metodologias ativas de aprendizagem somadas à percepção do ambiente e dos alunos;

- 19,04\% considera importante "gostar do que faz";

- 9,52\% afirma ser a vontade de "querer transmitir o conhecimento"/ disponibilidade para o ato de ensinar.

Fica evidente a ideia de que, para esses professores, é preciso existir uma associação do que se ensina na teoria com a prática, ou seja, é importante para a atuação desse docente o fato de atuar profissionalmente no campo do conhecimento que se está ensinando. Tal pensamento corrobora com a natureza dessa modalidade de ensino que ambiciona a Educação Profissional porém, é importante salientar que a ele está agregada a habilidade docente de manejo da sala de aula.

Acredito que a primeira coisa é querer ensinar, é querer estar disposto a repassar todo aquele seu conhecimento e experiência e em segundo, mas que tem com certeza muita importância é ter domínio sobre o assunto. (Prof.5).

[...] correlacionar os eixos trabalhados em sala com área do curso e com a realidade nacional, regional e local. (Prof. 9).

Dentre as competências docentes Zabalza (2005, p. 109) inclui a "seleção e a apresentação dos conteúdos disciplinares". Para ele, tal competência está vinculada a habilidade em selecionar os conteúdos a serem ensinados, diferenciando-os entre os essenciais, os necessários e os recomendáveis.

Entendo que a educação deve ser entendida a partir do público alvo, e que, a base tecnológica sendo a mesma o professor precisa ter este

Interfaces da Educ., Paranaíba, v.10, n.28, p.307 à 341, 2019 
cursor como norteador do saber educar. Com esse entendimento, posteriormente preciso do conhecimento sobre o tema, que através dos conhecimentos prévios deverá ter o ajuste conforme as mudanças tecnológicas e mercadológicas que remeterá a recorrer a busca de toda a informação que subsidiará para o desenvolvimento do saber e aplicar as técnicas de ensino pertinente a base de ensino. (Prof. 10).

Outro ponto que merece destaque é saber enfrentar situações inesperadas como, por exemplo, lidar com o déficit de aprendizagem do aluno e o uso do comportamento empático (capacidade de colocar-se no lugar do outro) de forma a melhorar a compreensão das expectativas/ necessidades dos estudantes. Conforme menciona Zabalza (1992, p. 67):

[...] dos alunos interessa-nos conhecer as suas características e experiências a nivel de background cultural, de aprendizagem e nível de desenvolvimento conseguido até esse momento, as suas formas básicas de adaptação à escola (ao estudo, aos companheiros, às exigências escolares, aos professores, etc.), de expectativas, etc.

Zabalza (2005, p. 97-98) também cita a tarefa do professor no sentido "pastoral" de estabelecer vínculo de empatia com seu aluno para que por meio desta conexão tenha a possibilidade (o poder) de trabalhar com ele.

[...] ao ensinar tecnologia é necessário ter grande domínio da ferramenta e manter-se sempre atualizado. Como comportamento é necessário que o docente faça sempre o exercício de empatia sempre se colocando no lugar do aluno para melhor poder avaliar e direcionar angústias, problemas e evolução educacional. (Prof. 13).

Em minha opinião, o professor precisa saber escutar os alunos e as pessoas e também ter o segundo olhar no que diz respeito a identificar oportunidades para melhorar, desenvolver e transformar realidades. (Prof. 21).

- Tipos de atividades realizadas além da docência.

Interfaces da Educ., Paranaíba, v.10, n.28, p.307 à 341, 2019 
Além da atividade de ensino propriamente dito, há outras que merecem destaque e que prevalecem entre àquelas realizadas pelo docente. Entre elas estão as:

- 71,42\% realiza atividades extracurriculares com relação direta a educação, entre elas: reuniões pedagógicas, planejamento coletivo, calendários de aulas, grupos de práticas pedagógicas, supervisão de estágio, conselhos de classe;

- 4,76\% também realizam atividades de apoio à administração da Instituição, sem relação direta com a atividade fim (educação);

- 4,76\% praticam formação contínua;

- $\quad$ 4,76\% mantém-se restritos à docência.

As atividades de planejamento individual ou coletivo, bem como o exercício do diálogo com os pares por meio das ações cotidianas que permitem a troca coletiva destacam-se como as mais praticadas.

Atividades extra salas, como por exemplo grupos para discussão de práticas pedagógicas, onde podemos discutir o dia-a-dia de sala e com a ajuda do grupo chegar a conclusões que ajudam na melhoria do processo ensino-aprendizagem. (Prof. 5).

Participação nos conselhos de classe, elaboração dos planos de aula, planejamento coletivo, elaboração da ficha individual do aluno, acompanhamento no desenvolver dos alunos no seu dia a dia, preenchimento do diário, reunião de áreas, acompanhamento de estágios, palestras orientativas. (Prof. 12).

Planejamento de aulas, participação de reuniões por área, geral, pedagógica, grupos de estudos, projetos, que no meu entendimento estão todas relacionados ao ato de ensinar, pois são nestas vivências que temos a oportunidade de refletir onde estamos acertando e onde estamos errando. (Prof. 17).

Segundo Franco (2011, p. 164), é preciso considerar que ensinar é uma prática social permeada por múltiplas articulações entre professores, alunos,

Interfaces da Educ., Paranaíba, v.10, n.28, p.307 à 341, 2019 
instituições e comunidades, infiltradas pelos contextos socioculturais as quais pertencem. Esse jogo de múltiplas confluências que se multideterminam num certo tempo e espaço social, impregna e configura a realidade existencial do docente. Sendo assim, o fazer docente estará sempre tomado das concepções de mundo, de vida e de existência, dos sujeitos da prática. O autor reitera que as condições institucionais são estruturais na determinação do papel que o docente pode ocupar para modelar sua prática.

O docente que não encontra na instituição condições de integrar-se num coletivo investigativo, num ambiente coletivo de mútuas aprendizagens, fica sem possibilidade de organizar-se como sujeito de sua práxis. Conforme realça Habermas (1982, p. 26), não há possibilidade de individualização sem socialização, assim como não há socialização possível sem individualizações. (p. 164-165).

- $\quad$ Conhecimentos específicos disciplinares necessários para o ensino.

Abaixo estão relacionados os materiais e fontes considerados os mais importantes, para os docentes participantes, quanto ao uso no exercício da docência. Merecendo destaque e ordenado do mais importante até o menos:

$\left.1^{\circ}\right)$ artigos científicos, livros, dissertações e teses;

$\left.2^{\circ}\right)$ sites não especializados. Entre os 21 participantes, uma pequena parcela $(23,80 \%)$ mencionou a consulta a sites de revistas científicas ou órgãos de classe, trabalhando com critérios para a elaboração e fornecimento de fontes de informação;

$\left.3^{\circ}\right)$ planos de cursos ou programas de cursos, entre outros documentos institucionais que norteiam as atividades docente;

$\left.4^{\circ}\right)$ jornais, revistas, quadrinhos, enquetes e apresentações eletrônicas disponiveis. Referindo-se aqui a fontes de informação sem critérios preestabelecidos para a pesquisa;

$\left.5^{\circ}\right)$ materiais compartilhados entre colegas de trabalho e/ ou a própria troca de experiências;

Interfaces da Educ., Paranaíba, v.10, n.28, p.307 à 341, 2019 
$\left.6^{\circ}\right)$ pesquisas de mercado.

Cabe ressaltar que, para a maioria, o livro ainda persiste como fonte principal de referência bibliográfica. Sendo que para as áreas regulamentadas, como por exemplo, a área da saúde, o uso de fontes de conhecimento reconhecidas por seus órgãos acreditadores figura entre as mais pesquisadas.

O plano de curso elaborado e estabelecido pelas instituições onde estes profissionais atuam serve de "documento vital" e é usado como referência sobre o perfil de conclusão do curso, objetivos do programa, conteúdos e referências bibliográficas básicas.

Utilizo como fonte norteadora o plano de curso, programa de curso, plano de aprendizagem, plano de orientação para a oferta e os documentos institucionais, bem como as referências bibliográficas que permeiam os cursos na qual ministro aula. Também consulto outras referências como livros/autores, artigos e sites de fontes confiáveis, tais como (Scielo, cátedra da UNESP e banco de dissertações e teses). (Prof. 3).

No Senac temos as ferramentas norteadoras que são os Planos de Curso e Planos de Orientação além do acervo bibliográfico, além destes, também recorro a várias fontes como: sites de diversos tipos, veiculação da informação na mídia para discussão de cases, Youtube, entre outros. (Prof. 10).

Com base no plano de aprendizagem fornecido pela instituição, é possivel o planejamento de aulas através buscas em sites acadêmicos, vídeos, dinâmicas, experiências positivas, leituras de textos e conhecimento prévio e de formação. (Prof. 14).

Nas respostas dos professores, os sites surgem como grande aliado porém, o fato de não de não haver um detalhamento acerca das referências, não é possivel avaliar a qualidade dessa ferramenta como fonte de informação fidedigna do conhecimento, o que pode vir a comprometer o conteúdo trabalhado em sala de aula se não observado.

Interfaces da Educ., Paranaíba, v.10, n.28, p.307 à 341, 2019 
- Dificuldades encontradas nas primeiras experiências docentes e formas de enfrentamento.

A falta de experiência no exercício da docência configura-se como principal dificuldade para a atuação docente, evidenciando uma desarticulação entre a formação na área específica e a formação para a docência.

As dificuldades encontradas forma algumas mas a principal seria a falta de experiência, vindo do trabalho em empresas e de repente estando em uma sala de aula mas como professor e sem nenhuma experiência foi sem dúvida a maior dificuldade. Essa e outras dificuldades foram superadas realizando atividades junto à instituição e na troca de experiências com outros docentes. (Prof. 5).

Ao terminar a graduação iniciei minhas atividades como enfermeira na área hospitalar juntamente com a oportunidade de supervisão de estágio e em seguida aulas em sala de aula, como não tinha a experiência pedagógica, encontrei dificuldades na parte burocrática de preenchimento de diário, vivência de planejamento de aula, tempo (por conta das 02 atividades concomitantemente). (Prof. 17).

Como apresenta Libâneo (2015, p. 8):

O problema não é a ênfase dada aos conteúdos específicos, mas a desarticulação entre a formação na área específica e a formação para a docência. O conhecimento pedagógico e o conhecimento disciplinar correm em paralelo, dissociados, aprofundando a desvinculação entre as metodologias de ensino e os conteúdos, entre métodos de ensino e métodos investigativos da ciência ensinada.

Como menciona Tardif (2000), as habilidades docentes têm forte caráter artesanal, que se edifica também no acompanhamento de um novo professor (aprendiz) em relação a um docente mais experiente.

No começo foi muito dificil, tinha experiência profissional, mas em sala de aula não, [...], fui aprendendo a cada dia com os docentes experientes e com os próprios alunos. (Prof. 7).

Interfaces da Educ., Paranaíba, v.10, n.28, p.307 à 341, 2019 
Tardif (2000, p. 14) também ressalta que os docentes servem-se do repertório vivenciado como alunos, constituindo seus próprios repertórios por meio de "tentativas e erros", ou como ele mesmo coloca, "às apalpadelas".

A minha primeira experiência como docente foi um desastre, nos primeiros 15 minutos eu dei a aula dos 120 minutos restantes de uma vez só. Mas depois ficou pior. Eu tinha o conteúdo da aula na ponta da língua, mas não tinha didática. Foi neste momento que percebi que tinha que exercitar a docência [...] Assim, me inseri para dar aulas em 'Ongs', instituições religiosas, realizar palestras públicas e etc. Foi através deste momento que aprendi muito com o exercício de ministrar aula. (Prof. 15).

Acredito que as primeiras dificuldades foram: aproximar a linguagem que na enfermagem é muito técnica do conhecimento dos alunos, não deixando as aulas ficarem desinteressantes. Para superar essa dificuldade passei dia a dia a acrescentar a linguagem técnica para os alunos e tentar fazer associações com termos cotidianos para facilitação da aprendizagem. (Prof. 20).

- Dificuldades atuais e projeções de formas de enfrentamento.

O perfil do aluno e as novas tecnologias, são os principais pontos destacados como dificuldades encontradas pelos docentes no exercício de sua profissão.

Atualmente, já não vejo como dificuldades e sim, desafios, devido as peculiaridades das turmas (pessoas) que estão chegando para este processo de ensino aprendizagem, onde entendo que exige uma atualização constante e uma flexibilidade do educador. (Prof. 14).

Shulman (2005, p. 18) menciona que estão presentes no ato de ensinar a operação e a norma, sendo que o conhecimento de base docente deve: focar em objetivos da educação, em métodos e estratégias de ensino. O autor prossegue com a ideia de que a compreensão do bom professor traz o estímulo aos processos construtivos, possibilitando/ fomentando no aluno o exercício de sua autonomia, o que para ser alcançado requer o exercício da empatia por parte do docente para produzir a transformação e interpretação do conhecimento a ser trabalhado/ apreendido.

Interfaces da Educ., Paranaíba, v.10, n.28, p.307 à 341, 2019 
Muitos alunos vêm para a escola com diversos problemas familiares $\mathrm{e}$, às vezes, desmotivados. Procuro manter um contato próximo com o aluno, fortalecendo a relação professor-aluno, desenvolvendo plenamente os valores e atitudes que permitam torná-los pessoas produtivas e autônomas. (Prof. 18).

As dinâmicas das novas tecnologias atraem muito a atenção, principalmente dos mais jovens, para tirar um jovem do Whatsapp a saída que encontrei foi estimular o uso do celular como ferramenta de troca de informações, busca de conteúdos, agendamento das tarefas entre outros, assim ganhamos um aliado. (Prof. 19).

Atualmente observo que os alunos têm muitas dificuldades básicas de aprendizado, não sendo essas dificuldades referentes ao curso, mas sim referentes ao ensino prévio que esses alunos tiveram. Para enfrentar essa dificuldade será necessário cada vez mais empenho, para que possamos passar o conhecimento técnico sem comprometimento das competências, tentando sempre recuperar o que for necessário e possivel. (Prof. 20).

- Ampliação da base de conhecimentos.

Abaixo estão listadas em ordem de prioridade as formas de conhecimento utilizadas para aprimoramento do ato de ensinar entre os profissionais avaliados. Destacando-se:

- $71,42 \%$ recorrem à leitura e discussões (diálogos) com os pares (grupos profissionais ou de classe) e com os alunos;

- 47,61\% se dedicam à formação continuada - por meio de cursos de curta ou longa duração;

- 4,76\% se apóiam na atuação profissional na área de conhecimento que trabalham;

- 4,76\% investem em atividades realizadas na própria instituição onde lecionam;

- $\quad$ 4,76\% também exercitam a auto avaliação da prática profissional.

- Tempo de dedicação aos estudos/formação continuada.

Quanto a quantidade de tempo dedicado aos estudos, é possível observar que poucos $(23,80 \%$ dos respondentes) possuem um valor

Interfaces da Educ., Paranaíba, v.10, n.28, p.307 à 341, 2019 
quantificado ou quantificável, sendo que expressões como "sempre que possivel", "entre uma aula e outra", "semanalmente", são as respostas que prevalecem. Aqueles que conseguiram quantificar o tempo dedicado aos estudos, mencionaram:

- 14,28\% dedica em média 2 horas diárias;

- 9,52\% dedica em média de 4 a 6 horas diárias.

O aprendizado adquirido em sala de aula, de forma individual ou por meio de trocas com outros pares de profissão, é incontestável no exercício da docência. Shulman (1986) corrobora com tal ideia referindo-se a "sabedoria da prática" como a forma particular de compreensão profissional onde, tais experiências dão sustentação às práticas dos professores, ou seja, as máximas que regem ou fornecem racionalizações reflexas para as práticas dos docentes talentosos.

Estar atento com as mudanças tecnológicas as exigências normativas e seus impactos, que através da leitura, contextualização com outros profissionais, me remete a confrontar com meus conhecimentos e rever pontos de atenção considerando os questionamentos que possam surgir durante as aulas sendo necessários um planejamento maior para atender todo impactos cultural e mercadológico. Para isso, semanalmente preciso interagir com os veículos de comunicação me atualizar, discutir certos pontos em questionamentos em grupos de profissionais em redes sociais. Um tempo estimado não consigo precisar, depende muito do tema e sua complexidade. (Prof. 10).

A atuação profissional também configura-se como ponto importante para aproximar a teoria da prática, propiciando ao docente o uso de estratégias metodológicas que facilitam o processo de ensino aprendizagem e a assimilação do conteúdo por parte do aluno. Para Zabalza (2005, p. 116) tal processo é denominado de repertório de metodologias, propiciando ao docente, quando existente, manejar a aula de maneiras distintas.

Interfaces da Educ., Paranaíba, v.10, n.28, p.307 à 341, 2019 
Estar sempre atualizado e dominar a ferramenta são imprescindiveis para uma boa aula para competências específicas. Sendo assim minha atualização tecnológica se dá através do Senac que oferece cursos da Educação Corporativa. O dia a dia através do meu outro trabalho pois sou Analista de Suporte Sênior em que vemos na prática e com isso é possivel expor cenários mais próximo da realidade e de maneira que possam estar preparados às situações do dia a dia no mercado de trabalho. O tempo destinado ao planejamento hoje é de 6 horas. (Prof. 13).

$\mathrm{Na}$ enfermagem a atualização do conhecimento se faz muito rapidamente e extremamente necessária, já que temos várias mudanças no cenário da saúde, dessa forma, sempre tento estar atenta as mudanças e atualizações através de leitura de normativas, cursos presenciais e online, entre outras fontes de saber. Às vezes, até assistir um telejornal nos traz atualizações para que possamos discutir atualidades da saúde com os alunos. (Prof. 20).

- Especificidades da docência no ensino técnico em nível médio.

Segundo os professores entrevistados, as principais especificidades da docência no Ensino Técnico em nível médio são os conteúdos relacionados à prática e a aderência da área de conhecimento. Quanto às especificidades, mencionaram:

- 33,33\% consideram ser o conteúdo aliado à prática;

- $28,57 \%$ sugeriu a formação na área do conhecimento (aderência) e a formação contínua;

- 9,52\% colocou em igualdade de importância as características: conhecimento acerca do perfil do aluno; trabalho em equipe e bom relacionamento interpessoal; trabalhar com as diferenças, seja de idade, escolaridade ou experiência profissional; consideração do conhecimento prévio do aluno; habilidades para a construção autônoma do conhecimento;

- 4,76\% deu o mesmo peso de importância para: autoconhecimento, flexibilidade, motivação, empenho, dedicação, capacitação, reinvenção,

Interfaces da Educ., Paranaíba, v.10, n.28, p.307 à 341, 2019 
humildade, resolução de conflitos; atuar por meio da mediação, estimulando a dúvida por parte do aluno; "gostar do que se faz".

Nota-se aqui uma dimensão bastante importante do ensino técnico, a interlocução com os saberes da vivência profissional. Saberes que são constituídos por meio do exercício profissional das áreas específicas de formação. Em sintese, é considerar que os saberes docentes do profissional que atua na educação profissional está além daqueles constituídos em seu ambiente de formação mas também, incluem-se àqueles obtidos em sua relação com o mundo do trabalho, enquanto profissional de determinada área do conhecimento.

Participação ativa no mercado de trabalho, bom relacionamento interpessoal, trabalho em equipe, facilidade de comunicação e expressão, busca de conhecimento pois principalmente na área de saúde que por trabalharmos com protocolos os mesmos mudam constantemente, comprometimento, responsabilidade, pois vamos atuar diretamente com "vidas", humildade, gostar de estar em contato com pessoas, valorizar o ser humano em todo o seu contexto. (Prof. 12).

Acredito que a necessidade de estarmos atento ao mercado atual, conhecimento específico, atualizações e buscar entender as diferentes formas do aprender. (Prof. 14).

Para Diniz-Pereira (1999, p. 112), “a crença de que para ser bom professor, basta o domínio da área do conhecimento específico que se vai ensinar, é um equívoco do modelo da racionalidade técnica". O que é reforçado nos estudos de Oliveira (2006, p. 5):

[...] há uma tradição no sentido de se considerar que, para ser professor, o mais importante é ser profissional da área relacionada à(s) disciplinas que se vai lecionar ou que leciona. O professor do ensino técnico não é concebido como um profissional da educação, mas um profissional de outra área e que nela também leciona.

Em suas pesquisas, Negrini e Cruz (2008), demonstraram que na formação dos professores estão presentes marcas do elo fábrica-escola e que

Interfaces da Educ., Paranaíba, v.10, n.28, p.307 à 341, 2019 
estas vão sendo ressignificadas durante a atuação docente no decorrer de sua trajetória pessoal e profissional, em um processo de formação contínua.

O ensino técnico prepara o aluno diretamente para o mercado de trabalho, e cabe aos docentes além de passar conhecimentos técnicos, preparar os alunos para a realidade vivenciada no dia a dia do trabalho. (Prof.20).

- Desenvolvimento profissional da docência e politicas institucionais.

No que tange a definição de uma política de desenvolvimento profissional da docência frente a instituição em que atua, os professores pesquisados destacam entre as suas citações, por prioridade das respostas:

- 85,71 respondeu ser o investimento contínuo em formação continuada;

- 9,52\% citou a realização de atividades extracurriculares tais como, reuniões pedagógicas, cursos, palestras (workshops), diálogos acerca da prática profissional; e,

- 4,76\% mencionaram igualitariamente: investimento na construção da identidade profissional ou profissionalização docente; participação em encontros técnicos promovidos por órgãos de classe; destinação da parte da carga horária docente para o planejamento das aulas e a definição de uma política de cargos e salários.

Imbernón (2004, p. 69-70) menciona alguns pilares ou principios no qual se fundamentará no futuro a formação permanente docente, citando entre elas a formação no lugar de trabalho, na própria instituição educacional.

O Senac oferece uma politica de Formação Contínua que é a melhor que já tive conhecimento, com reuniões pedagógicas mensais, formações pedagógicas periódicas e técnica/específicas pela Educação Corporativa. Não consigo pensar num modelo melhor pois sempre estou desenvolvendo e atualizando metodologia e didático aliado ao que há de mais recente e inovador no mercado de tecnologia. (Prof. 2).

Ao longo destes 12 anos na instituição tive muitas oportunidades de desenvolvimento e consegui colocar em práticas muito do aprendizado vivido, acredito que focar em especialização na área da psicopedagogia

Interfaces da Educ., Paranaíba, v.10, n.28, p.307 à 341, 2019 
iria agregar conhecimento para minha prática diária, mas como temos profissionais na instituição que de uma certa forma exercem esta atividade tento comunicação mais próxima para melhorar as resoluções de conflito que aparecem no decorrer das situações. (Prof. 17).

\section{Ainda cita o mesmo autor que:}

[...] a formação deve apoiar-se em uma reflexão dos sujeitos sobre sua prática docente, de modo a lhes permitir examinar suas teorias implícitas, seus esquemas de funcionamento, suas atitudes etc., realizando um processo constante de auto avaliação que oriente seu trabalho, consistindo em descobrir, organizar, fundamentar, revisar e construir a teoria. Se necessário, deve-se ajudar a remover o sentido pedagógico comum, recompor o equilíbrio entre os esquemas práticos dominantes e os esquemas teóricos que os sustentam. (Imbernón, 2004, p. 55).

- $\quad$ início da docência no ensino técnico em nível médio.

Desafio, apreensividade, surpresa, solidão e insegurança são os sentimentos que caracterizam os primeiros dias de aula. A partir deles, a revisão contínua do seu "fazer docente" e o passar dos dias (tempo/ experiência), são aliados fundamentais para a aquisição/ consolidação de um repertório docente para manejo da classe (Zabalza, 2005).

Quando iniciei no Ensino Técnico fui chamado para desenvolver um conteúdo de Linux e logo no primeiro dia a classe me questionou se ia trabalhar a questão ou somente iria "tapar buraco" e com isso o desafio se agravou. A primeira aula não conseguiu despertar o interesse nos alunos e creio que foi extremamente teórica, replanejei as aulas sempre com uma introdução teórica e logo após com uma intervenção prática e isso deu muito certo que sigo esse modelo até hoje. Mesmo assim creio que o início foi muito dificil não havia material disponível, a internet era restrita, não havia profissionais a quem consultar ou compartilhar conteúdos e nunca havia trabalhado com um público noturno, que trabalhava e de uma faixa etária tão diversa entre 18 e 45 anos. (Prof. 2).

Interfaces da Educ., Paranaíba, v.10, n.28, p.307 à 341, 2019 
Meus primeiros dias foram desafiadores, pois precisei buscar conhecimento sobre assuntos que conhecia apenas na faculdade e outros que possuía a pratica e precisei procurar a teoria. Tive um pouco de dificuldade na interpretação do plano de aprendizagem e do método de abordagem com os alunos, pois estava acostumada com outro tipo de acompanhamento em outra empresa, a qual na época senti a falta da integração para saber de alguns pontos específicos. Exemplos: Em sala de aula, minha primeira base foi a "Arquitetura Organizacional" na Administração a qual tive certa dificuldade do que ministrar e mesmo solicitando a colegas não consegui a resposta adequada. Perguntas como: quais itens devo abordar, tempo, e material didático. Após minuciosa leitura do plano de aprendizagem, consegui interpretá-lo melhor, e somente após algum tempo obtive conhecimento que estava disponivel na intranet todos os arquivos necessários. O público alvo, composto por adolescentes em sua maioria muito desafiadores, tornando meu trabalho mais árduo e eficaz, em busca de conhecimento constante para evitar erros e tropeços, procurando trazer o máximo de informação necessária ao grupo. (Prof. 4).

A reflexão contínua sobre "o que se faz" e "como se faz" como conhecimento para a formação e/ ou aprimoramento da atuação docente, o que está respaldado pela teoria da reflexão sobre a ação ou conhecimento na ação, defendida por Schön $(1983,1987)$.

Relembrando meu primeiro dia, quando cheguei fiquei um pouco perdida, pois a única orientação que tive foi aonde pegar o diário e a sala aonde estaria, isto me causou um pouco de insegurança até mesmo porque fui até a sala sozinha para iniciar uma atividade que nunca havia praticado. Mas saiu melhor do que esperava pois o conteúdo que ministrei era de conhecimento prático, então isto me tranquilizou um pouco e fez com que eu me soltasse. Pouca orientação voltada para o funcionamento da instituição, normas e rotinas. Eu vinha no dia determinado, ministrava a aula, preenchia o diário e "só". Se o discente me questionava sobre algo que estava acontecendo ou iria acontecer na instituição não sabia responder, ia atrás da resposta mas era bem difícil. Tinha muitas dúvidas e muitas vezes não sabia a quem perguntar. Entrava nas turmas as vezes com o conteúdo que me foi solicitado, aí os alunos traziam que já haviam visto este

Interfaces da Educ., Paranaíba, v.10, n.28, p.307 à 341, 2019 
conteúdo, era uma sensação muito ruim, pois isto nos dá a impressão de desorganização, com isso também fui aprendendo a me preparar para diversos imprevistos, de alguma forma também aprendia com estas situações. Muitas vezes a turma ou a aula mudava no dia ou melhor no horário que você chegava, pois alguém faltou, aconteceu alguma coisa. Me fez lembrar também das pessoas que me acolheram e me ajudaram durante este tempo. (Prof. 12).

Como todo início de qualquer coisa, tive minhas incertezas. Uma delas foi o de trabalhar com outras ferramentas no qual não fosse sugeridas no plano de aula; se eu poderia levar exemplos do cotidiano e/ou experiências própria para sala de aula, bem como outros tipos de atividades; estudos de caso, etc. E com o tempo senti-me mais à vontade, não fico mais "presa" ao que somente é solicitado; entendi que lançar mão de outros instrumentos enriquecia muito o conteúdo trabalhado e os alunos identificavam com maior facilidade. (Prof. 14).

Estava acostumada a ministrar aulas em uma escola de ensino particular e a maneira como ensinava era bem diferente do jeito Senac de educar. Acredito que nesta escola não tínhamos a liberdade de fazer diferente, precisava seguir a apostila e pronto, era um ensino bem tradicional. Quando entrei no Senac e participei de um curso (PDE), fiquei maravilhada com a didática, além de poder pesquisar e trazer para a sala de aula, dinâmicas, vídeos, enfim tudo que era pertinente ao conteúdo que precisava ensinar, mas com liberdade de escolher e fazer diferente. (Prof. 18).

Já tinha a vivência de sala de aula em outra instituição, porém em nivel de graduação, e o ensino técnico é muito desafiador, os alunos são curiosos e se o docente não estiver preparado pode ficar em situações constrangedoras. Isso pra mim foi muito bom pois a cada dia me preparava mais e mais para poder dar sempre aos alunos uma construção do conhecimento embasada cientificamente e com conteúdo. (Prof. 20).

- Práticas pedagógicas relatadas.

Quando os professores participantes ponderam sobre uma aula já dada, desde o momento do planejamento à execução, eles relatam que, o sentimento de ter atingido o objetivo proposto no plano de aula, ao analisarem as 
respostas dos alunos frentes aos exercícios propostos, traz a sensação de prazer ao profissional docente. A reflexão sobre a ação (Schön, 1983, 1987) permite o aprimoramento contínuo, fazendo com que a sua atuação seja diferenciada e assertiva frente aos conteúdos trabalhados.

A aula foi planejada durante a elaboração do plano de aula, a execução ocorreu na sala de aula, uma vez em que inicia-se também a análise da aula. O momento da reflexão da ação que ocorreu na aula se dar por vários momentos após a execução da aula, sendo fundamental para a elaboração das próximas aulas, a partir das considerações e percepções. (Prof. 1).

As aulas sempre foram planejadas com antecedência, mas em algumas vezes não aconteciam como imaginava e isso gerava ao mesmo tempo uma decepção, mas ao mesmo tempo fazia-me pensar que na próxima aula algo teria que ser diferente e assim a cada dia melhorava a forma de ensinar, dessa forma entendo que o processo de ensino é sem dúvida um aprendizado constante, nunca acertamos a formula correta e sim todo dia encontramos para aquele dia a fórmula certa, felizmente ensinar não e nunca será uma ciência exata. (Prof. 5).

Precisei ministrar algumas competências de um módulo do qual eu não tinha total domínio. Como tive de recordar muitos cálculos específicos da competência, imaginei que a turma também teria bastante dificuldade, pois o curso é voltado para comunicação, e normalmente, eles temem esse assunto. Planejei aulas bastante práticas e passo-a-passo. Desenvolvi uma avaliação individual, para tentar perceber a dificuldade de cada um. A medida em que entregaram, percebi as expressões de medo e que as respostas estavam erradas. Mudei na hora a minha estratégia, pois levaria o material para corrigir em casa e no segundo periodo entraria com outro conteúdo. Nesse momento, devolvi todas as atividades à turma e passei individualmente, trabalhando a dificuldade um a um, e só sosseguei, quando toda a sala me entregou as atividades $100 \%$ corretas. Queria ter a certeza de que todos aprenderam. Tentei, inclusive, trabalhar a questão do medo de cálculo, por parte de alguns alunos. A turma gostou muito da experiência, e no final da aula, me

Interfaces da Educ., Paranaíba, v.10, n.28, p.307 à 341, 2019 
agradeceram. Jamais esquecerei, pois foi prazeroso para ambos. (Prof. 8).

No momento de planejar, retomo o Plano de Trabalho Coletivo desenvolvido pela área, na sequência verifico os eixos e atividades solicitadas pelo PO, em seguida monto o plano de aula, defino as estratégias, as atividades que serão desenvolvidas e os recursos necessários para agendar. Normalmente, planejo e monto todas as aulas da respectiva competência. A execução consiste na aplicação do planejamento, mediando conforme dúvidas e participações da turma. A análise é feita no dia seguinte, modificando a próxima aula, acrescentando algum item se for necessário. (Prof. 9).

O "olhar" docente para o perfil de cada turma é fundamental na proposta de atividades de acordo com esta realidade. O tempo na atividade docente permite o desenvolvimento de uma sensibilidade "acurada" para questões acerca das estratégias de aprendizagem face ao perfil do alunado.

Pegando como base essa aula, eu pensei na importância de "enxergar" micro-organismos, ver que mesmo uma mão limpa pode contaminar objetos e pacientes, transmitir doenças e até matar. Isso é dificil de entender quando não se vê a mão suja, por isso pensei em mostrar que mesmo não vendo a mão suja, os micro-organismos estão lá. Tive que entrar em contato com laboratório para conseguir estufa de crescimento e rever a técnica para que crescesse micro-organismos. Hoje se fosse dar a aula de novo faria várias placas, uma sem lavar, outra lavando sem técnica, outra lavando com técnica e outra com degermação cirúrgica, para que os alunos consigam ver a diferença de cada uma delas. (Prof. 11).

Uma aula que me lembro sempre é uma que foi logo no início de docência, onde o objetivo era trabalhar a autoestima e reconhecimento de valores no outro e apliquei uma dinâmica de talentos, e que numa outra turma tinha dado super certo, ou pelo menos o que eu esperava, na oportunidade ficamos todos muito sensibilizados, porém naquela turma, em minha opinião, ficou muito "pobre", não teve o mesmo resultado da experiência anterior, fiquei muito frustrada. Fiquei pensando: "só isso?", "Houve todo um planejamento, o que será que

Interfaces da Educ., Paranaíba, v.10, n.28, p.307 à 341, 2019 
aconteceu?", "Será que sou exigente demais?" "A outra turma era melhor?"

Após uma reflexão, tirei a seguinte conclusão: cada turma é única e possui sua especificidade. Além disso, o docente tem que ter condições de um olhar diferenciado, sensivel para cada turma e a partir disto propor atividades que realmente vão promover o desenvolvimento "daqueles" alunos. E não é que uma atividade teve um resultado com uma turma, a outra necessariamente precisa ter o mesmo. (Prof. 14).

Apliquei uma dinâmica para as 03 turmas de enfermagem que estavam em andamento, pois o objetivo da dinâmica era trabalho em equipe assunto este que para as 03 turmas não estavam conseguindo realizar. Para a primeira turma fiz o plano de aula conforme solicitado no impresso e apliquei na sala de aula fazendo as devolutivas pertinentes a dinâmica, pois era uma turma grande e já tinha um envolvimento maior com os alunos por se tratar de uma turma que estava terminando o curso, achei que por ter dado certo com esta turma poderia aplicar para as outras 02 turmas da mesma forma e meu erro foi não ter olhado para o perfil dos demais alunos antes de aplicar a dinâmica e não ter feito novo planejamento e adaptação da dinâmica conforme necessidades individuais embora o objetivo fosse o mesmo - trabalho em equipe, as vivencias e experiências colocadas foram diferentes da primeira turma o que dificultou o entendimento dos alunos e a própria dinâmica em si. Hoje continuo aplicando esta dinâmica, pois o resultado final para os alunos é surpreendente, mas antes de planejá-la analiso os perfis dos alunos e devolutivas dos demais docentes para que o feedback seja individual e o objetivo seja coletivo. (Prof. 17).

A prática por parte do aluno também é fundamental para a aprendizagem. Roldão (2007) argumenta:

[...] o professor profissional é aquele que ensina não apenas porque sabem mas porque sabe ensinar. Saber ensinar é ser especialista da complexa capacidade de transformar o saber curricular mediado por um saber científico, por um domínio técnico-didático rigoroso, por uma postura meta-analítica, de questionamento intelectual da ação,

Interfaces da Educ., Paranaíba, v.10, n.28, p.307 à 341, 2019 
de interpretação permanente e realimentação contínua, para que o aluno aprenda de forma contextualizada e com significado.

O planejamento ocorre conforme o perfil do público, mais jovens os conteúdos acabam sendo mais dinâmicos e interativos, já os mais velhos gostam de teorias e então o desenvolvimento da prática com atividades menos expositivas. Cada nova turma é um aprendizado, cada aluno é único, cada nova aula é uma experiência diferente mesmo que os alunos sejam os mesmos, cada dia é único na docência, e quanto mais tempo convivemos vamos aprendendo que sabemos muito pouco, ou quase nada. (Prof. 19).

Para Burnier (2006):

O magistério na educação profissional não aparece como opção profissional inicial da grande maioria desses docentes e, a partir do momento em que ingressaram na carreira, são atraídos pelas relações que estabelecem, sobretudo com os alunos, o que lhes proporciona uma forte gratificação por se sentirem contribuindo para a formação de outras pessoas.

Sob a ótica dos professores pesquisados, a trajetória da docência no Ensino Técnico em nivel médio é caracterizada inicialmente por sentimentos que remetem ao desafio, apreensividade, surpresa, solidão e insegurança. A falta de experiência para o exercício da docência configura-se como principal dificuldade para a atuação, evidenciando uma desarticulação entre a formação na área específica e a formação para a docência.

O decorrer do tempo e a revisão contínua do seu "fazer docente" são os aliados fundamentais para a aquisição/consolidação de um repertório profissional para manejo da classe. Dessa forma, os professores superam as dificuldades encontradas e desenvolvem o "olhar" docente para o perfil de cada turma, propondo atividades de acordo com esta realidade. O tempo na atividade docente permite o desenvolvimento de uma sensibilidade "acurada" para questões acerca das estratégias de aprendizagem face ao perfil do alunado.

Interfaces da Educ., Paranaíba, v.10, n.28, p.307 à 341, 2019 
Aprendizagem da docência de professores do Ensino Técnico...

As aprendizagens da docência são obtidas por diversos meios, sendo que a trajetória profissional como ponto de partida para a inserção na educação/formação concomitante à atuação como docente é a forma que prevalece. Tal caminho profissional em particular, dialoga diretamente com as especificidades desta modalidade de ensino. Uma dimensão bastante importante do Ensino Técnico, está na interlocução com os saberes da vivência profissional. Saberes que são constituídos por meio do exercício profissional das áreas específicas de formação. Isto é, os saberes docentes do profissional que atua na educação profissional está além daqueles constituídos em seu ambiente de formação mas também, incluem-se àqueles obtidos em sua relação com o mundo do trabalho enquanto profissional de determinada área do conhecimento. Assim, tem-se que a associação daquilo que se ensina na teoria com a prática ou, o fato de atuar profissionalmente no campo do conhecimento que se está ensinando, predomina. O que é justificável quando nos referimos a uma modalidade de ensino com vistas à Educação Profissional porém, é importante salientar que a ela está agregada a habilidade docente de manejo da sala de aula.

Ainda no que tange ao desenvolvimento dos conhecimentos específicos disciplinares, para a maioria dos profissionais, o livro ainda persiste como fonte principal de referência. Sendo que para as áreas em que há regulamentação da área, uso de fontes do conhecimento reconhecidas por seus órgãos acreditadores também está entre as mais pesquisadas. Outro instrumento que se mostrou importante foi o plano de curso estabelecido pela instituição de ensino, uma vez que, a partir dele, é possível se apoiar em informações como o perfil de conclusão do curso, objetivos do programa, conteúdos e referências bibliográficas básicas. Também contribui para essa construção de conhecimentos, as leituras e discussões (diálogos) com os pares (grupos profissionais ou de classe) e os alunos.

Em relação a outras atividades exercidas, as mais praticadas são as de planejamento, seja individual ou coletivo, bem como, os diálogos com os pares por meio das ações cotidianas que permitem a troca coletiva.

Interfaces da Educ., Paranaíba, v.10, n.28, p.307 à 341, 2019 
O investimento em formação continuada é amplamente reconhecido como necessário e um importante meio de desenvolvimento profissional, sendo que, no caso dos professores pesquisados, é grande o nível de satisfação com relação à política implementada pela instituição em que atuam.

\section{Considerações finais}

Ao longo do tempo é possivel observar na Educação a dualidade entre a elite dominante e a classe trabalhadora. Para o trabalhador, o Ensino Técnico sempre esteve restrito como meio de formação de mão de obra operária para oficios/profissões de base. Talvez por isto, sua regulamentação seja arcaica e os estudos acerca dele, mínimos.

É evidente a necessidade de promover o debate e os estudos acerca desta modalidade, a começar pela legislação que deixa a desejar no que tange a definição de regulamentação. O Ensino Técnico muito se beneficiaria de uma política nacional ampla própria para a modalidade, para o perfil profissional daquele que nela atua e para os programas de formação para o seu exercício.

Deste ponto deriva uma das questões abordadas neste estudo, as trajetórias de aprendizagem do profissional do ensino técnico. Por trajetória de aprendizagem entende-se o saber derivado da prática (ou experiencial) como principal meio de formação. É o conhecimento que advém do exercício diário e, por vezes, consequência de um modelo preexistente, que quando vivenciado na condição de aluno ou do ensaio e erro, tentativa e acerto, do compartir ideias junto a colegas mais experientes, na troca cotidiana, da reflexão sobre a ação.

O aprendizado da teoria associado à prática, uma das característica mais importantes do Ensino Técnico, traz à figura do docente uma dimensão fundamental pois, é por meio da consolidação dos seus conhecimentos de base e/ ou competências necessárias ao exercício de sua profissão que ele promoverá espaços de aprendizagem necessários para a vivência da prática. Por esse motivo, é de suma importância a necessidade de refletir sobre e 
consolidar esforços para a formação do docente nas diversas etapas de suas vidas profissionais.

Imbernón (2004, p. 46) cita Bolam (1980) durante sua participação na Conferência Intergovernamental de Paris onde argumentava que:

As dificuldades encontradas nestes anos no que se refere a programas de formação [...] revelaram, por um lado, a pouca consideração da experiência pessoal e profissional dos professores, de suas motivações, do meio de trabalho - em suma, de sua situação de trabalhadores - e, por outro, a participação insuficiente dos interessados na tomada de decisões que lhes concernem diretamente. [...] Os professores devem poder beneficiar-se de uma formação permanente que seja adequada às suas necessidades profissionais em contextos educativos e sociais em evolução.

Ao docente cabe a atitude problematizadora e mediadora no processo de ensino-aprendizagem, consolidando práticas educacionais, como diria Paulo Freire (1980), “para além de uma educação bancária”. Porém, é preciso superar a fragmentação, improviso e insuficiência pedagógica evidenciados por meio de uma política para a formação docente consolidada.

Paralelamente, a instituição educacional possui papel de fundamental importância nessa trajetória de aprendizagem por meio de políticas de estímulos à formação continuada. Dessa forma, contribui para a minimização da lacuna existente entre a formação inicial e a atuação docente do profissional de determinada área do conhecimento. Por isso, ainda em Imbernón (2004, p. 114), tem-se que a formação deve se aproximar da prática educativa no interior das instituições educacionais. O contato da formação com a prática educativa faz com que o conhecimento profissional se enriqueça em outros âmbitos como o moral e ético, além de permitir que se desenvolva a reflexão sobre a prática educativa. Nesse contexto, é possível buscar uma recomposição deliberativa dos esquemas, concepções e crenças que o conhecimento pedagógico tem sobre o ensino e aprendizagem, para que seja viável trabalhar em benefício do professor e da educação da humanidade.

Interfaces da Educ., Paranaíba, v.10, n.28, p.307 à 341, 2019 
Finalmente, apesar da educação não ser responsável por todos os sucessos e insucesso da sociedade, a ela ainda resta o controle de importantes condições do processo de ensino aprendizagem.

Qualidade... a gente sabe o que é, e, ao mesmo tempo, não sabe. Isso é contraditório. Mas algumas coisas são melhores do que outras, ou seja, têm mais qualidade. Porém, se a gente tenta definir qualidade, isolando-a das coisas que a possuem, então puf! - já há o que falar. Se, no entanto, não se pode definir qualidade, como sabemos o que ela é, ou como sabemos que ela existe? Se ninguém sabe o que é, então, para todos os efeitos, não existe. Senão, em que se baseariam as notas? Por que as pessoas pagariam fortunas por algumas coisas, jogando outras no lixo? Naturalmente, algumas coisas são melhores que outras... Mas o que é "ser melhor"? E aí a gente começa a dar voltas que não acabam mais, fazendo girar rodas mentais sem encontrar um ponto de apoio que nos possibilite a arrancada para a viagem. Que diabo é qualidade? (Pirsig, 1974).

\section{Referências bibliográficas}

ANDRÉ, Marli. A produção acadêmica sobre formação de professores: um estudo comparativo das dissertações e teses defendidas nos anos 1990 e 2000. Formação docente - Revista Brasileira de Pesquisa sobre Formação de Professores, Belo Horizonte, volume 1, número 1, p. 41-56, maio/2009. Disponivel em: <http://formacaodocente.autenticaeditora.com.br $>$. Acesso em: 05 maio. 2010.

BRASIL. [Lei de diretrizes e bases da educação nacional]. Lei de diretrizes e bases da educação: (Lei 9.394/96) / apresentação Carlos Roberto Jamil Cury. - 9. Ed. - Rio de Janeiro: DP\&A, 2005.

BRZEZINSKI, Iria. Formação de Profissionais da Educação (1997-2002). Série Estado do Conhecimento, Brasília, MEC/Inep, n. 10, 2006.

CHARLOT, Bernard. A Pesquisa Educacional, entre Conhecimentos, Políticas e Práticas: especificidades e desafios de uma área de saber. Revista Brasileira 
de Educação, Rio de Janeiro, ANPEd - Associação Nacional de Pós-Graduaç̃̃ e Pesquisa em Educação, v. 11, n. 31, p. 7-18, jan./abr. 2006.

FREIRE, Paulo. Conscientização: teoria e prática da libertação. São Paulo: Editora Centauro, 1980.

HUBERMAN, Michael. O ciclo de vida profissional dos professores. In: NÓVOA, António Sampaio (Org.). Vidas de Professores. Porto: Porto Editora, p. 31-46. 1992.

IMBERNÓN, Francisco. Formação Docente e Profissional: formar-se para a mudança e a incerteza. São Paulo: Cortez, 2004.

MESSEDER, Hamurabi. Entendendo a LDB: Lei de Diretrizes e Bases da Educação Nacional Lei n. 9.394/1996. Rio de Janeiro: Editora Elsevier, 2012.

MOURA, D. H. A formação de docentes para a educação profissional e tecnológica. Boletim técnico do Senac: a revista da educação profissional / Senac, Departamento Nacional. Rio de Janeiro, v. 41, n. 1, p. 23-38, jan./abr. 2015.

SHULMAN, Lee. Those Who Understand: knowledge growth in teaching. Educational Researcher, Londres, v. 15, n. 2, p. 4-14, fevereiro. 1986.

SHULMAN, Lee. Truth and Consequences: inquiry and policy in research on teacher education. Journal of Teacher Education, Stanford, v. 53, n. 3, p. 248253, maio. 2002.

SHULMAN, Lee. Conocimiento y Enseñanza: fundamentos de la nueva reforma. Profesorado, revista de currículum y formación del profesorado, Granada, v. 9, n. 2, p. 1-30. 2005.

TARDIF, Maurice e RAYMOND, Danielle. Saberes, tempo e aprendizagem do trabalho no magistério. Educação e Sociedade, Campinas, v. 21, n 73, p. 209244, dezembro. 2000.

TARDIF, Maurice e LESSARD, Claude. O Trabalho Docente: elementos para uma teoria da docência como profissão de interações humanas. Petrópolis: Editora Vozes, 2007.

ZABALZA, Miguel Angel. El Trabajo por Competências em la Enseñanza Universitaria. Jornades D'Innovación Docent de la Universidad de Barcelona, 4, p. 1-26, agosto. 2007.

Interfaces da Educ., Paranaíba, v.10, n.28, p.307 à 341, 2019 
ZABALZA, Miguel Angel. O Ensino Universitário: seus cenários e protagonistas. Porto Alegre: Editora Artmed, 2004.

ZABALZA, Miguel Angel. Competencias Docentes. Conferencia pronunciada em la Pontificia Universidad Javeriana de Cali. Santiago de Compostela, Espanha, p. 87-125, fevereiro. 2005.

ZABALZA, Miguel Angel. Planificação e Desenvolvimento Curricular na Escola. Portugal: Editora ASA, 1992.

ZABALZA, Miguel Angel. Ser Profesor Universitário Hoy. La Cuestión Universitaria, Madri, n. 5, p. 69-81. 2009.

Interfaces da Educ., Paranaíba, v.10, n.28, p.307 à 341, 2019 